\title{
EIח反A
}

Revista Eletrônica de Estudos Integrados em Discurso e Argumentação

\section{DISCURSO HUMORÍSTICO EM PROPAGANDAS DE TRÂNSITO: EFEITOS IDEOLÓGICOS DA CULTURA DE NEGATIVAÇÃO DA MORTE}

\author{
Mercia Sylvianne Rodrigues Pimentel ${ }^{i}$
}

Resumo: Este artigo propõe uma reflexão crítica acerca da relação entre morte, humor e ironia a partir da análise do discurso de uma campanha educativa de trânsito sobre o perigo de misturar álcool e direção. Para tanto, são tomadas como materialidades discursivas peças de comunicação (outdoors) sobre a temática dessa campanha. Como arcabouço teórico norteador, tem-se a Análise do Discurso francesa, de vertente pecheutiana, somada ao referencial dos dispositivos analíticos. Embora a campanha de trânsito tenha trazido uma proposta diferenciada ao associar morte e humor para chamar a atenção dos condutores no sentido de evitar acidentes, a análise do material coletado demonstrou, entre outros aspectos, ser a morte banalizada pela propaganda, assim como haver um reforço à reprodução da cultura de negativação da morte na sociedade contemporânea.

Palavras-chave: Discurso. Morte. Humor. Ideologia.

\begin{abstract}
This paper proposes a critical reflection about the relation between death, humour and irony based upon a discoursive analysis of a traffic safety education campaign on the danger of mixing alcohol ingestion and driving. We will take as discursive materialities outdoors pertaining to this campaign. As theoretical framework, we draw upon both the pecheutian approach to Discourse Analysis and the perspective of analytical devices. Although the traffic campaign has brought a different association between death and humour in order to draw the attention of drivers towards avoiding accidents, the analysis of the collected material showed, among other things, a trivialization of death, as well as a reinforcement of the reproduction of the culture of negativization of death in contemporary society.
\end{abstract}

Keywords: Discourse. Death. Humor. Ideology.

i Doutora em Letras e Linguística pela Universidade Federal de Alagoas (UFAL) e docente da mesma universidade. E-mail: msrpimentel@yahoo.com.br. 
EID\&A - Revista Eletrônica de Estudos Integrados em Discurso e Argumentação, Ilhéus, n. 11, jan/jun.2016.

\section{Introdução}

Desde a Antiguidade, a temática do humor acompanha a produção teórica de vários estudiosos. O homem é o único animal que ri, já afirmava Aristóteles (2010), constatando a potencialidade fisiológica do ser humano para o riso. Porém, quando se trata da morte, rir soa como 'algo que não tem graça', dada a cultura de negativação da morte $^{1}$ herdada pelas civilizações ocidentais e tão propagada na contemporaneidade.

Embora a ideia de morte provoque a sensação de temor entre os sujeitos, práticas da propaganda vêm fazendo com que ela ganhe uma conotação diferente: a morte nos anúncios é trabalhada de maneira jocosa, criando um imaginário de aparente positividade, de forma a atrair a atenção do consumidor para a venda de produtos e serviços funerários e para a propagação de ideias dominantes.

Levando isso em consideração, este trabalho pretende compreender os efeitos de sentido possibilitados pela análise de propagandas que fazem o uso da comicidade na abordagem da morte. Para tanto, são tomadas como materialidades discursivas peças de comunicação (outdoors) que versam sobre a temática da morte produzidas para uma campanha de trânsito sobre a relação perigosa entre bebida e direção. Considerando que imagem também traz discursos, por, entre outras razões, ser fruto de uma construção simbólica cujo funcionamento aponta para derivas de sentido via linguagem não-verbal, os enunciados são trabalhados em sintonia com os elementos pictóricos, pois juntos eles formam o "todo discursivo".

"Bebeu e está dirigindo? Vai ficar lindo com uma coroa de flores" ou "Igreja lotada daqui a sete dias" estão entre os enunciados contidos nas materialidades e submetidos à análise. Como base teórica, utilizamos dispositivos teóricos da Análise do Discurso pecheutiana, bem como contribuições de outras áreas do conhecimento, como a Antropologia, para melhor compreender a significação da morte na sociedade ocidental contemporânea.

\footnotetext{
1 O conceito de negativação da morte foi trabalhado em nossa tese de doutorado intitulada "Morte-mercadoria na sociedade contemporânea: análise dos discursos de negativação e positivação da morte no capitalismo", defendida no Programa de Pós-Graduação em Letras e Linguística da Universidade Federal de Alagoas (PPGLL/UFAL). O discurso sobre a morte nas relações sociais contemporâneas sofre o efeito da negativação, ou seja, a morte é posta como algo negativo, instância violenta que tira do ser a possibilidade de realizar-se, além de provocar os sentidos de perda, tristeza, sofrimento e medo, dentre outros.
} 
EID\&A - Revista Eletrônica de Estudos Integrados em Discurso e Argumentação, Ilhéus, n. 11, jan/jun.2016.

Interessante observar que na sociedade atual a palavra "morte" evidencia sentidos como os de "mau agouro" e "mau gosto", mas se for para vender uma ideia ou um produto, é tomada como bem-vinda. Instaura-se, assim, mais um paradoxo da sociabilidade capitalista: a sociedade que, ao mesmo tempo, nega a presença e o real da morte faz com que eles sejam "ressuscitados" via humor, de modo a reproduzir interesses dominantes por intermédio da ideologia.

Embora a sociedade ainda se revista de temor em relação à morte, percebemos a recorrência de efeitos discursivo-ideológicos de ironia e humor nas materialidades publicitárias contemporâneas que versam sobre essa temática. Pensando a ironia como forma específica de interdiscurso (BRAIT, 2008) e o humor como a capacidade de percepção e criação do cômico (PROPP, 1992), procuramos compreender as materialidades trabalhando os efeitos dos enunciados-imagens que se utilizam do discurso humorístico, em resumo, constituídos de ironia, cinismo e humor.

\section{A ironia, o real e a ideologia no funcionamento do discurso humorístico}

A princípio, morte e riso parecem ocupar posições antagônicas se pensados numa mesma esfera de discussão; possibilitam sentidos opostos se refletidos enquanto efeitos do simbólico ${ }^{2}$. Balizada na cultura de negativação, a ideia de morte propagada na sociedade contemporânea está associada à de fim, perda, pessimismo, dentre outras que expressem negatividade. Por outro lado, o riso se relaciona a sentimentos de euforia, felicidade, vitória, otimismo e outros expressos num espectro de positividade. Nesse sentido, morte e riso não se coadunam, uma vez que ocupam planos semânticos que se contrapõem³.

Ambos os fenômenos (morte/riso) apresentam sentidos opostos, mas também vários pontos de contato. Assim como para a morte, a explicação para o fenômeno do riso ou do que faz rir, o risível, ainda é considerada enigmática. Segundo Possenti (2010, p. 51), as causas do riso são comumente associadas a três aspectos: rebaixamento (físico ou moral), economia psíquica acompanhada de recalque e a técnica. "É bem provável que, em numerosos

\footnotetext{
${ }^{2}$ Simbolicamente, morte remete à tristeza; enquanto que o riso suscita alegria.

${ }^{3}$ Apesar de falarmos em morte, não estamos considerando a morte em si, mas as representações e sentidos que ecoam sobre ela, conforme assinala Rodrigues (2011).
} 
EID\&A - Revista Eletrônica de Estudos Integrados em Discurso e Argumentação, Ilhéus, n. 11, jan/jun.2016.

textos jocosos, os três elementos, ou pelo menos dois, funcionem em conjunto, de forma que o efeito de humor é, a rigor, sobredeterminado".

Para Propp (1992), o humor seria a capacidade de perceber e criar o cômico, provocando o riso; sendo a ironia uma de suas faces, acrescentamos. Essa capacidade de "percepção" e "criação" da comicidade não se dá no vazio, é atravessada por determinações sócio-históricas, pelo funcionamento da ideologia que se materializa nos discursos.

A ideologia, na perspectiva discursiva, funciona de modo a refletir e refratar o real sócio-histórico, a luta de classes, reproduzindo ora discursos dominantes ora manifestando anseios das minorias. Como as contradições sociais estão no cerne da formação social capitalista, as desigualdades entre as classes e os sujeitos são deslocadas para o imaginário das piadas, que são gêneros discursivos. Como disse Pêcheux (1997b, p. 255), "O real existe, necessariamente, independentemente do pensamento e fora dele, mas o pensamento depende, necessariamente, do real, isto é, não existe fora do real". Assim, piadas sobre mulheres, negros, gays e outras minorias circulam e fazem as pessoas rirem não porque são genuinamente engraçadas, mas por serem frutos de relações interdiscursivas oriundas de um real cujas práticas sociais põem os sujeitos em situação de desigualdade.

A ironia, sendo efeito do interdiscurso na linguagem (BRAIT, 2008), consiste em afirmar o contrário do que foi dito, mas só funciona se 0 interlocutor souber a que se refere a informação veiculada, ou seja, estiver consciente do conteúdo transmitido. A ironia é constituinte do discurso humorístico, pois, como afirma Voese (1992), ele contém um jogo de sutilezas, sendo a sátira carregada de ironia e caricatura verbal para criticar fatos ou condutas que não são desejáveis. Para o autor, o humor irônico ao "[...] criar um sentido diferente do sentido convencional do enunciado significa a produção de um discurso de alta complexidade e de alto poder de efeitos de sentido, e que exige, dos interlocutores, habilidades especiais que a interação discursiva, em outros casos, não exige" (VOESE, 1992, p. 15).

A depender da temática abordada, a propaganda se utiliza de ironia e humor para difundir ideias cuja aceitação social encontra algum tipo de resistência, como é o caso da morte. No caso dos outdoors da campanha de trânsito recolhidos para análise, temos a propaganda funcionando ideologicamente, "vendendo" ideias e sentidos pré-construídos (estereótipos e senso comum) de uma pseudoaproximação com a temática da morte. 
EID\&A - Revista Eletrônica de Estudos Integrados em Discurso e Argumentação, Ilhéus, n. 11, jan/jun.2016.

2. “Bebeu e está dirigindo?": os sentidos de negativação da morte

Uma abordagem analítica do discurso passa pela compreensão de suas condições de produção (CP), visto que ele não é reflexo de abstrações nem elucubrações do sujeito, mas efeito da práxis social. Discurso é, no dizer de Pêcheux (1997a), efeito de sentido entre interlocutores, provém da realidade sócio-histórica inscrita na língua para significar. Como todo discurso é produzido em circunstâncias específicas do fazer histórico, mostra-se necessária a reflexão sobre as condições que possibilitaram sua emergência. Para tanto, são levados em consideração os contextos amplo e restrito de produção/circulação dos enunciados, de modo que sejam apreendidas filiações e deslocamentos de sentidos.

As materialidades discursivas recolhidas para análise versam sobre a divulgação de uma campanha educativa de trânsito sobre a relação perigosa entre álcool e direção, permeada por sentidos de morte e humor. Considerando os aspectos ideológicos dos sentidos de negativação (cultura ocidental de afastamento da morte, pondo-a como algo negativo) e simulação de positividade (estetização da morte para torná-la aceitável), coletamos quatro outdoors postos em vias públicas da cidade de Belém/PA, no ano de 2006, assinados pela agência publicitária WT Gomes, como pode ser identificado nas imagens abaixo. Além de Belém, a campanha chegou a várias capitais brasileiras, tendo também circulado exaustivamente na internet via correio eletrônico.

\section{Figura 1 - Imagem em outdoor com o tema "Coroa de Flores".}

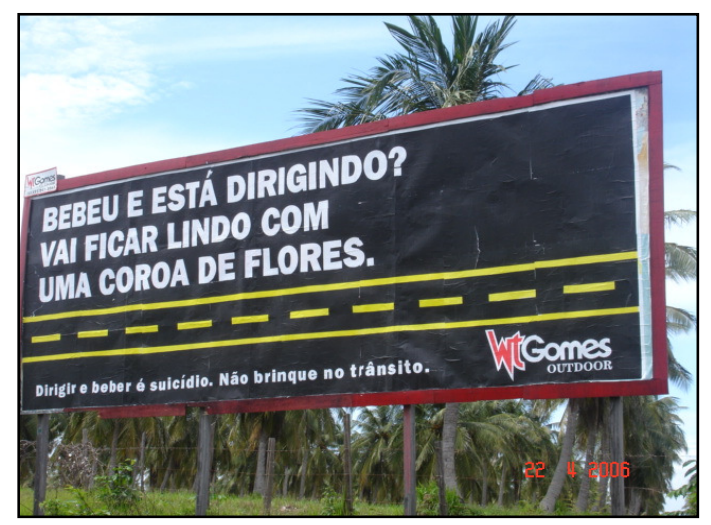

Fonte: http://www.imgrum.net/media/1153116147512307476_685243898. 
EID\&A - Revista Eletrônica de Estudos Integrados em Discurso e Argumentação, Ilhéus, n. 11, jan/jun.2016.

Figura 2 - Imagem em outdoor com o tema "Missa de $7^{\circ}$ dia".

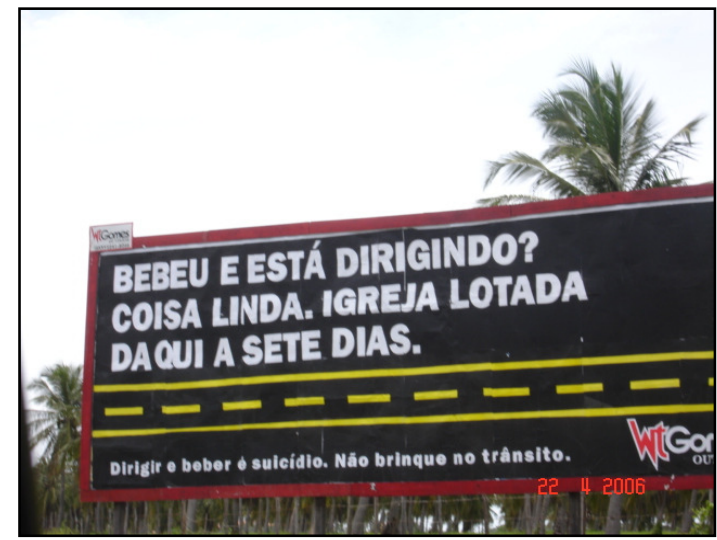

Fonte: http://www.imgrum.net/media/1153116147512307476_685243898.

Figura 3 - Imagem em outdoor com o tema "Cremação".

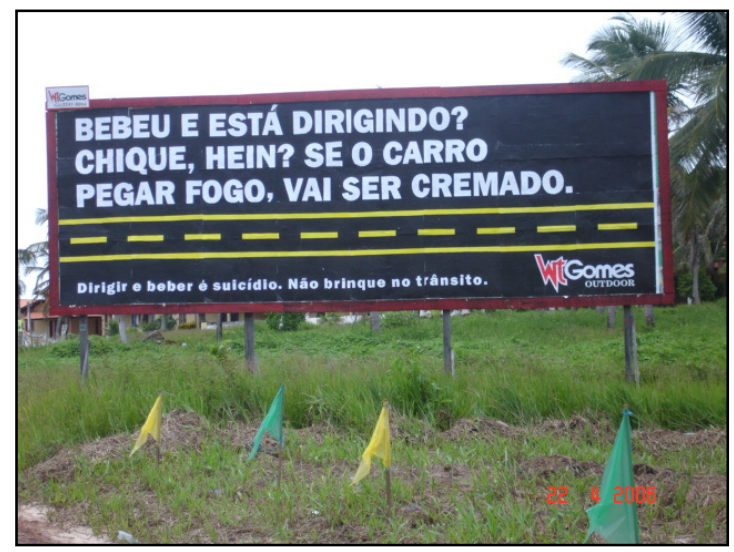

Fonte: http://www.imgrum.net/media/1153116147512307476_685243898.

Figura 4 - Imagem em outdoor com o tema "Testamento".

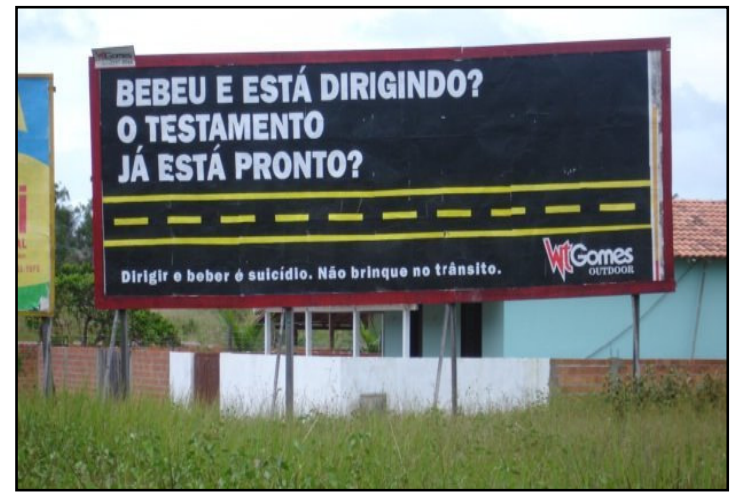

Fonte: http://www.imgrum.net/media/1153116147512307476_685243898. 
EID\&A - Revista Eletrônica de Estudos Integrados em Discurso e Argumentação, Ilhéus, n. 11, jan/jun.2016.

No campo da AD materialista, é comum entre analistas de discurso o uso da expressão "efeitos de sentido" em suas abordagens, isso porque retomam a clássica definição de discurso encontrada em Pêcheux (1997b), segundo a qual o discurso funciona como efeitos de sentido produzidos por sujeitos afetados pela língua e pela história. $O$ discurso não se confunde com a fala nem com a língua, apesar de operar sobre uma materialidade linguística constituída pela estrutura da língua em constante ruptura.

Causando "efeitos" e não o sentido verdadeiro e único, o discurso provoca evidências que serão desmistificadas no momento em que são analisadas. Afirma Pêcheux (1997b, p. 160) que o sentido não existe "em si mesmo", mas é determinado pelas posições ideológicas em jogo, construção posteriormente retomada por Orlandi (1996, p. 27) ao mencionar o caráter histórico do sentido: ele "[...] não está já fixado a priori como essência das palavras, nem tampouco (sic) pode ser qualquer um: há a determinação histórica". A partir dessa percepção de que os sentidos mudam conforme o movimento sócio-histórico, produzindo efeitos também distintos, procuramos perceber, de modo lato, os efeitos discursivos materializados nos enunciados-imagens.

A imagem de fundo das quatro peças de comunicação é a mesma, porém os enunciados são distintos. Como se trata de uma campanha de trânsito, as placas trazem à memória a visualização do asfalto com a faixa amarela sinalizada como forma de regulação do fluxo de veículos. O fundo negro lembra o asfalto, que é preenchido com o branco dos enunciados e o amarelo representativo das faixas contínua e descontínua de trânsito, as quais remetem aos sentidos de ultrapassagem proibitiva (faixa contínua) e permitida (faixa tracejada).

A cor preta não só imita a pista, como também remete a um dos símbolos do luto. Nessa junção entre texto, cores e símbolos, percebemos o interdiscurso funcionando, ou seja, aquilo que fala antes, noutro lugar, de modo "independente"; já-dito que circula na realidade social e se organiza na memória, possibilitando a emergência e o movimento de novas relações de sentidos (PÊCHEUX, 1997b). Os sentidos de morte e embriaguez no trânsito dialogam entre $\mathrm{si}$, sendo esse gesto interpretativo confirmado a partir da construção "Dirigir e beber é suicídio. Não brinque no trânsito", situada próximo à assinatura da agência publicitária.

Além disso, na expressão "Dirigir e beber é suicídio. Não brinque no trânsito", há a ressignificação do slogan "Se beber, não dirija; se dirigir, não 
EID\&A - Revista Eletrônica de Estudos Integrados em Discurso e Argumentação, Ilhéus, n. 11, jan/jun.2016.

beba" cristalizado socialmente por meio das inúmeras campanhas de educação no trânsito sobre essa temática, o que nos faz perceber a interdiscursividade presente nesses slogans. $O$ enunciado contido nesta campanha de 2006 reforça o sentido de "culpa" atribuído aos sujeitos envolvidos em acidentes, quando aponta para o condutor a responsabilidade por seus atos.

O condutor que tenha ingerido álcool e, consequentemente, venha a sofrer algum tipo de acidente no trânsito não será enquadrado como "vítima", e sim como "suicida", pois "Dirigir e beber é suicídio", segundo o enunciado. Uma possível leitura dessa mudança de slogan se deve ao fato de querer produzir um impacto maior, que leve a uma mudança de atitude, pois o "Se beber, não dirija" repetido insistentemente numa forma mais modalizada parece não ter produzido o efeito desejado, dado o crescente aumento de vítimas de acidentes e mortes no trânsito ${ }^{4}$.

Outro aspecto comum a todas as placas é a presença da ironia e do humor, que, embora provoque o riso com a sátira da morte, finaliza em tom de seriedade. Como se o sujeito da propaganda, o órgão de fiscalização, fosse autorizado a "brincar" com a situação, mas o condutor, não. Por isso, o tom imperativo do enunciado final "Não brinque no trânsito", que pode ser completado com a explicativa "pois você poderá morrer". A ordem de não brincar no trânsito carrega o não-dito da morte como penalidade, a morte negativada que aparece como uma sanção para os que "brincam" com algo exposto como sério.

"Coroa de flores", "cremação", "viúva", "missa de $7^{\circ}$ dia" e "testamento" são expressões/palavras comuns no universo discursivo dos rituais mortuários, sobretudo cristãos. Na primeira sequência discursiva "Vai ficar lindo com uma coroa de flores" (Figura 1), percebemos, pelo tom irônico da assertiva, uma tentativa de provocar o riso e, ao mesmo tempo, o temor à morte. De acordo com Possenti (2010), o discurso humorístico veicula sentidos censurados ou proibidos, os quais não viriam à tona sem a "vitalidade" desse discurso. O autor destaca ainda que textos humorísticos são construídos sobre lugares comuns e estereótipos, explorando-os de um modo diferente do convencional, o que pode ser observado nos enunciados da campanha.

${ }^{4}$ Segundo Relatório do IPEA, DENATRAN e ANTP (2006), no ano de 2004 ocorreu uma média de 307 acidentes por dia em rodovias federais, o que totalizou 112.457 ao ano. 
EID\&A - Revista Eletrônica de Estudos Integrados em Discurso e Argumentação, Ilhéus, n. 11, jan/jun.2016.

Sabemos que o emprego do adjetivo "lindo" se dá em expressões elogiosas, o que não corresponde à construção acima. Nisso se instala a ironia, pois a palavra está sendo colocada num campo semântico diferente do usual, o "lindo" funciona como uma repreensão do tipo "bonito isso, hein?". o mesmo ocorre em "Coisa linda. Igreja lotada daqui a sete dias", no qual o "lindo" também está posto de forma irônica. Na formação discursiva religiosa cristã, brincar com os rituais e cerimônias religiosos soa como ato profano, sendo proibidas expressões como as dos recortes citados. Nessa FD, o discurso religioso predomina, de modo que a hierarquização de papéis é representada pela demarcação entre Deus/Cristo (locutor) e fiéis/cristãos (ouvintes). Isso nos faz rememorar o quanto, no dizer de Propp (1992), religião e riso se excluíam de modo recíproco, deixando algumas marcas dessa exclusão na atualidade.

O riso na igreja durante o serviço religioso era considerado sacrilégio. Entretanto, deve-se fazer ressalva de que o riso e a alegria não são incompatíveis com todas as religiões; essa incompatibilidade é característica da ascética religião cristã, mas não daquelas da Antiguidade, com suas saturnais e ritos dionisíacos (PROPP, 1992, p. 35).

Embora essa tenha sido uma realidade do catolicismo da Idade Média, sabemos que algumas práticas ainda perduram, como a de não poder dar risadas dentro da Igreja, por se tratar de um lugar de oração e de respeito ao divino. Mas, de acordo com Silva (2006):

O humor tende a profanar o sagrado. No fundo do nosso ser, rimos dos nossos medos e das nossas crenças. Piadas sobre santos, o paraíso e o inferno são comuns entre os cristãos simples que não se veem pecando ao pensar e rir sobre o sobrenatural.

Ou seja, apesar de haver interdição, o riso do proibido sempre escapa, pois o ritual ideológico também produz falhas (PÊCHEUX, 1997b). Desse modo, o discurso propagandístico atravessa o religioso para fazer o sujeito rir do proibido, mesmo que seja num outro campo semântico.

Retomando o primeiro enunciado "Vai ficar lindo com uma coroa de flores", no contexto da sociedade contemporânea, ocidental e cristã, como o nosso, não há imagem de beleza num corpo coroado de flores. A coroa de flores metaforiza a morte, que aparece de maneira negativa através do ar sombrio provocado pelo luto da imagem. Como assinala Rodrigues (2011, p. 200): "A negação da morte e a invenção da Morte são um fato específico da sociedade industrial, fruto da oposição vida/morte que nossa cultura não sabe 
EID\&A - Revista Eletrônica de Estudos Integrados em Discurso e Argumentação, Ilhéus, n. 11, jan/jun.2016.

integrar. Enquanto as outras culturas privilegiam a continuidade, a nossa cultua a ruptura" entre vida e morte. Em virtude dessa visão dissociativa entre vida e morte, os sujeitos da sociedade contemporânea (excetuando as culturas tradicionais) não veem beleza nos signos da morte (caixão, cemitério, jazigo, urna funerária etc.).

Essa ideia de morte como negação foi trazida por Imedio (apud RIBEIRO, 2008, p. 5) quando afirmou que:

No mundo moderno, a morte está escondida como algo sujo e vergonhoso, sinônimo de absurdo, horror e sofrimento; algo escandaloso e insuportável. A ideia que se quer defender é a de que o sujeito não deve combinar álcool e direção, caso contrário, será recebido pela 'indesejada das gentes's.

Tanto a missa de $7^{\circ}$ dia, ritual tradicional da Igreja Católica, como a morte são banalizadas, expostas como alvos de brincadeira. Ao brincar com a morte, o discurso humorístico presente na propaganda cria um efeito de aparente positividade, por sugerir uma aproximação com a temática; no entanto, a ideia de desconforto perante a morte acompanha todas as construções enunciativas. Trata-se da reprodução dos sentidos de negativação da morte, os quais mencionamos no início do texto e que são frutos da cultura ocidental de banimento da morte enraizada no Brasil.

Em "Bebeu e está dirigindo? Chique, hein? Se o carro pegar fogo, vai ser cremado" (Figura 3), acreditamos que o riso provocado assume o aspecto de zombaria, uma definição discutida por Propp (1992) na compreensão do cômico em obras literárias. Segundo o teórico, o riso de zombaria é o tipo de riso que mais encontramos na vida, por isso ele afirma ser esse tipo merecedor de maior atenção. Nas palavras do autor, é possível rir do homem em quase todas as manifestações, porém faz-se necessário descobrir o que se mostra engraçado.

Às vezes, é o próprio indivíduo que revela involuntariamente os lados cômicos de sua natureza, de suas ações; outras, ao contrário, quem o faz propositalmente é quem zomba. Aquele que zomba comporta-se da mesma maneira tanto na vida como na arte. Existem procedimentos especiais para mostrar o que é ridículo na aparência, nas ideias ou nas atitudes de um indivíduo (PROPP, 1992, p. 29).

A acepção do termo "ridículo" empregado por Propp (1992) não é a de sentido pejorativo, como vemos frequentemente, mas a de algo que suscita $\mathrm{o}$

${ }^{5}$ Expressão pela qual Manuel Bandeira (1993) costumava se referir à morte. 
EID\&A - Revista Eletrônica de Estudos Integrados em Discurso e Argumentação, Ilhéus, n. 11, jan/jun.2016.

riso. Assim, no riso de zombaria, tanto a figura humana, quanto suas ideias, aspirações, objetivos são ridicularizados distintamente. Associamos esse tipo de riso ao encontrado no cartaz, porque a propaganda zomba do homem e da morte a partir da ideia de cremação. Por esse processo o cadáver é reduzido a cinzas, num procedimento que acelera a decomposição do corpo, e o que o humor do cartaz faz é sugerir que o condutor que bebe e dirige ao mesmo tempo está antecipando sua morte. A expressão "chique, hein?" traz a ironia ao mesmo tempo em que satiriza uma das significações culturais de se guardar o defunto.

Percebemos, no enunciado "Bebeu e está dirigindo? O testamento já está pronto?" (Figura 4), a remissão ao testamento como uma das consequências da morte. Diferente das outras materialidades, que trouxeram o discurso religioso como FD dominante, esta sequência discursiva nos permite compreender que a memória de testamento como um ato religioso se dilui para dar lugar ao imaginário de testamento como um instrumento de divisão de bens, daí o questionamento "já está pronto?", que reforça a posição do sujeito moderno capitalista cuja preocupação reside no objeto e não no sujeito. Esse sentido de testamento como objeto rentável é trazido por Rodrigues (2011) quando explica a passagem do testamento como instrumento religioso para jurídico:

Assim laicizado o testamento foi se transformando em instrumento exclusivamente jurídico que pouco ou nada mais faz que distribuir bens e fortunas. Mais precisamente, ele se transformou em instrumento de redistribuição do capital familiar, principalmente quando o morto fosse também o chefe da família. Na nova sociedade é imprescindível que este capital continue dentro da família e é obrigação de todos fazê-lo frutificar e multiplicar. Não se concebe mais que as riquezas legadas possam ser consumidas. Pelo contrário, o novo credo quer que sejam rentabilizadas (RODRIGUES, 2011, p. 128).

Assim, ao cumprir seu papel de transferir riquezas entre os viventes, o testamento mencionado na citação e na sequência discursiva acima provoca o efeito de preocupação no sujeito-condutor, no sentido de evitar a antecipação dessa finalidade, pois, caso não siga a orientação da campanha, vai sentir o peso da responsabilidade "no bolso". Ao tentar trazer a morte a partir de uma perspectiva engraçada, diferente da forma que é vista frequentemente, esse e os outros enunciados acabam por esvaziá-la. $O$ efeito de evidência de que a morte está sendo trabalhada de maneira positiva se apaga quando observamos que a propaganda se utiliza dela para criar um espectro de temor 
EID\&A - Revista Eletrônica de Estudos Integrados em Discurso e Argumentação, Ilhéus, n. 11, jan/jun.2016.

nos condutores, pois, assustados com a figura da morte, passariam a dirigir de forma responsável.

Como veiculadora de interesses de grupos hegemônicos, a propaganda nesta situação discursiva está a serviço de um órgão do Estado, um Departamento de Trânsito. Embora manifeste preocupação com o futuro dos condutores, o conteúdo da materialidade discursiva também aponta para um não-dito: o de que acidentes devam ser evitados para não gerar mais gastos públicos, pois quanto mais mortes, mais despesas com o pagamento de seguros e indenizações ${ }^{6}$.

\section{Considerações finais}

Este artigo trouxe como ponto central para reflexão o discurso de negativação da morte materializado em propagandas institucionais que promoviam uma pseudoaproximação dos sujeitos com a temática (simulacro de positivação) mediante utilização de recursos como ironia e humor. Para isso, tomamos como materialidade discursiva cartazes (outdoors) que versam sobre a temática da morte produzidos para uma campanha de trânsito, com vistas a orientar condutores sobre o perigo da combinação de bebida e direção.

De acordo com as análises, percebemos que a morte só se mostra positiva na propaganda se for para vender a ideia da campanha e, para isso, ela teria que se associar ao riso. Mas essa positividade é aparente, já que continuam sendo produzidos sentidos de negatividade em torno dela: a relação apresentada na propaganda é de causa e consequência, ou seja, se o condutor não se portar bem nas vias quanto à ingestão de álcool, será levado à morte.

Os enunciados trazem a temática da morte pelo viés do humor para provocar o riso nos condutores e, a partir disso, "vender" a ideia de que a mistura entre álcool e direção não combina. $O$ riso é empregado de modo a intentar apagar o real: rir-se para não perceber as distorções, os desvios e os deslocamentos de uma "indústria da consciência" que influencia na representação da morte como um assunto que ainda é tabu entre nós, embora seja um fenômeno natural e certo.

${ }^{6}$ O Relatório do IPEA, DENATRAN e ANTP (2006) apresenta os impactos sociais e, sobretudo, econômicos decorrentes de acidentes de trânsito nas rodovias brasileiras. 
EID\&A - Revista Eletrônica de Estudos Integrados em Discurso e Argumentação, Ilhéus, n. 11, jan/jun.2016.

O sujeito da propaganda brinca com a religião, com a espiritualidade e com outros valores culturais que dizem respeito à finitude humana sem desprendimento. O humor e a ironia presentes no discurso propagandístico funcionam de modo a legitimar práticas veladas de escamoteamento da morte, pois embora essa temática seja recorrente nas campanhas de trânsito, sua simples inserção não induz os sujeitos a um posicionamento reflexivo, pelo contrário, zomba da realidade discrepante e não contribui para alterá-la.

\section{Referências}

ARISTÓTELES. Parte dos animais. In: MESQUITA, António Pedro. Obras completas de Aristóteles. Trad. Maria de Fátima Sousa e Silva. Lisboa: Imprensa Nacional - Casa da Moeda, 2010.

BANDEIRA, Manoel. Poesia completa e prosa. Rio de Janeiro: Nova Aguilar S. A., 1993.

BRAIT, Beth. Ironia em perspectiva polifônica. Campinas: Editora da Unicamp, 2008.

IPEA, DENATRAN, ANTP. Impactos sociais e econômicos dos acidentes de trânsitos nas rodovias brasileiras. Brasília: Relatório Executivo, 2006.

ORLANDI, Eni. Interpretação: autoria, leitura e efeitos do trabalho simbólico. Petrópolis: Vozes, 1996.

PÊCHEUX, Michel. Análise automática do discurso (AAD69). In: GADET, F.; HAK, T. Por uma análise automática do discurso: uma introdução à obra de Michel Pêcheux. Trad. Jonas de A. Romualdo. 3. ed. Campinas, SP: Editora da Unicamp, $1997 a$.

. Semântica e Discurso: uma crítica à afirmação do óbvio. Tradução de Eni Orlandi et al. Campinas: Edunicamp, 1997b.

PIMENTEL, Mercia. Morte-mercadoria na sociedade contemporânea: análise dos discursos de negativação e positivação da morte no capitalismo. 2015. 202f. Tese (Doutorado em Letras e Linguística). Maceió: Universidade Federal de Alagoas, 2015.

POSSENTI, Sírio. Humor, língua e discurso. São Paulo: Contexto, 2010.

PROPP, Vladimir. Comicidade e riso. São Paulo: Ática, 1992

RIBEIRO, Euler Esteves. Tanatologia: vida e finitude. Rio de Janeiro: UERJ, UnATI, 2008. 
EID\&A - Revista Eletrônica de Estudos Integrados em Discurso e Argumentação, Ilhéus, n. 11, jan/jun.2016.

RODRIGUES, José Carlos. Tabu da morte. 2. ed. Rio de Janeiro: Fiocruz, 2011.

SILVA, Antônio Ozaí. Entre o sagrado e o profano: o interdito ao riso. REA, $n^{\circ} 58$, mar.2006. Disponível em: <http://www.espacoacademico.com.br/058/580zai.htm>. Acesso em 15 out. 2014.

VOESE, Ingo. O discurso humorístico: um estudo introdutório. Leitura, Revista do Departamento de Letras Clássicas e Vernáculas, CHLA-UFAL, Maceió, n. 5-6, jan.-dez. 1989-90, p. 7-20, 1992.

Forma de citação sugerida:

PIMENTEL, Mercia Sylvianne Rodrigues. Discurso humorístico em propagandas de trânsito: efeitos ideológicos da cultura de negativação da morte. EID\&A - Revista Eletrônica de Estudos Integrados em Discurso e Argumentação, Ilhéus, n. 11, p. 89102, jan/jun.2016.

Recebido em: 20/02/2016

Aprovado em: 21/06/2016 